\title{
Development of a modular CHP test stand for the analysis of the dynamic behaviour of small synchronous generators
}

\author{
Philipp Erlinghagen $\bowtie$, Mathias Knaak, Tilman Wippenbeck, \\ Armin Schnettler \\ Institute for High Voltage Technology (IFHT), RWTH Aachen University, Aachen, Germany \\ 凶E-mail: erlinghagen@ifht.rwth-aachen.de
}

\begin{abstract}
Within this study, the development and implementation of a modular test stand for small combined heat and power plants (CHPs) with directly coupled synchronous generators (SGs) is presented. The test stand's design allows an easy emulation of different engine and governor concepts by the use of a highly dynamic electrical drive. Additionally, the mechanical design enables an easy exchange of the SG, being the device under test. The test stand can be used to validate the transient behaviour of dynamic SG models. Furthermore, the test stand is integrated into a laboratory in the Testing Center at the IFHT where it can be tested within various low-voltage test grid topologies, including further distributed energy resources, loads, and other low-voltage assets. Exemplary test results for one specific control and SG set-up in islanded operation are shown. The test stand's design presented in this study can be used as a draft for similar laboratory set-ups.
\end{abstract}

\section{Introduction}

Owing to the increasing number of distributed energy resources (DERs) with dynamic grid support requirements, active distribution grids (ADGs) become more important for transient stability analyses [1]. In order to include ADGs into transient stability studies, time domain models for DERs are needed. Today, the validity of dynamic DER models is a major challenge [2]. One way of facing this problem is the validation of the models and their parameterisations against real-life devices. One DER technology is the directly coupled synchronous generator (SG), mainly used in combined heat and power plants (CHPs) in German low-voltage grids [3].

Within this paper, an insight into the planning and implementation details for the development of similar test stands is given. The exemplary tests in this paper focus on the transient behaviour of the test stand during large active and reactive load variations in an islanded grid.

\section{Planning and design}

To be able to test a large variety of different SGs and control schemes, a modular design is used with the combination of an electric motor and generator. The electric drive is a highly dynamic asynchronous machine (ASM) - instead of a gas or diesel engine - to be able to emulate the behaviour of different types of engine and governor concepts. To adopt different control concepts for both, the motor and the generator, an embedded control system with a real-time operating system including an field programmable gate array (FPGA) is used. The device under test used in the following is a real-life SG that can be found in many small-scale CHPs in Germany.

\subsection{Electrical and mechanical design}

The overall power layout of the test stand is $50 \mathrm{~kW}$. In order to fulfil today's and future grid codes [4], an $84 \mathrm{~kW} \mathrm{SG}$ (four poles at $50 \mathrm{~Hz}$ and $1500 \mathrm{rpm}$, respectively) with a standard AVR is used, which can supply $105 \mathrm{kVA}$ at a power factor of 0.8 . To emulate a large variety of gas engines, a highly dynamic ASM with $63.75 \mathrm{~kW}$ power at a speed of $1500 \mathrm{rpm}$ in combination with a servo inverter with a maximum power of $110 \mathrm{~kW}$ are used. A speed and torque measuring flange for a maximum torque of $5 \mathrm{kN} \mathrm{m}$ and a maximum speed of $10,000 \mathrm{rpm}$ is used. The components are mounted on a cast iron machine bed as shown in Fig. 1 (see the Appendix for the real set-up and for a complete list of the components used).

All mechanical parts need to be compatible concerning their maximum mechanical stresses. The coupling, being the central connecting element between the rotating masses, is of major importance for the whole mechanical layout. The maximum torque at the coupling can be calculated as follows: the maximum braking torque of the SG at a three-phase short circuit of $M_{\text {brake }}=10.1 \mathrm{kN}$ m needs to be split onto the different components of the mechanical link as shown in Fig. 2 with $M=J \times \dot{\omega}$ ( $J$ being the inertia). The maximum braking power of the motor is $M_{\text {acc }}=802 \mathrm{~N} \mathrm{~m}$.

The overall inertia is calculated as $J_{\text {overall }}=J_{\text {drive }}+J_{\text {coupl }}+$ $J_{\text {meas.fl }}+J_{\text {fl }}+J_{\text {gen }}=(0.303+0.045+0.038+0.035+0.791) \mathrm{kg} \mathrm{m}^{2}$. The braking torque that is transmitted from the generator to the motor over the coupling can be calculated as

$$
M_{\text {brake, }}=\left(J_{\text {drive }}+\frac{J_{\text {coupl }}}{2}\right)\left(\frac{M_{\text {brake }}}{J_{\text {overall }}}\right)
$$

The torque that is transmitted from the motor to the generator over the coupling can be calculated as

$$
M_{\text {acc }, \mathrm{c}}=\left(\frac{J_{\text {coupl }}}{2}+J_{\text {meas.fl }}+J_{\text {fl }}+J_{\text {gen }}\right)\left(\frac{M_{\text {acc }}}{J_{\text {overall }}}\right)
$$

Using the values for this specific set-up, the maximum torque at the coupling is $M_{\text {max }, \mathrm{c}}=M_{\text {brake, } \mathrm{c}}+M_{\mathrm{acc}, \mathrm{c}}=3.3 \mathrm{kN} \mathrm{m}(<5 \mathrm{kN} \mathrm{m})$. 


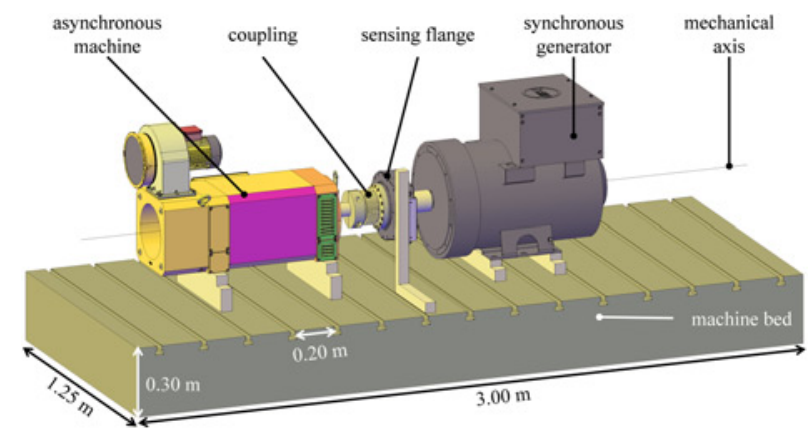

Fig. 1 Set-up of the main mechanical components

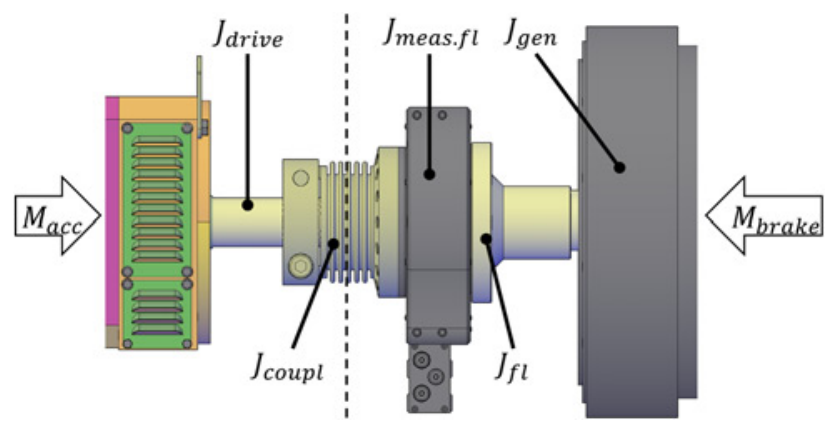

Fig. 2 Components of the mechanical link

\subsection{Control design}

The design of the electrical wiring of the components can be split into four main parts: functional safety (personal security), intrinsic safety (monitoring of system boundaries), control, and measurement. The following parameters need to be monitored during operation: temperatures, frequency/speed, voltage, overcurrent, re-/active power, exciter voltage, and communication/ measurement errors. The layout of the interactions between the physical components and the communication parts is shown in Fig. 3.

\section{Implementation}

\subsection{Automatic voltage regulator}

A standard, hard-wired automatic voltage regulator (AVR) is used (Fig. 4) [5]. This AVR is a state of the art product that is regularly used in CHPs. Therefore, it is suitable for a realistic emulation of common CHPs' electrical behaviours. The AVR does not depend on inputs from the measurement and control system. It comprises, among others, a lag element of the voltage measurement $\left(T_{1}, T_{2}\right)$, a proportional amplifier $\left(K_{\mathrm{p}}\right)$, an integrator $\left(K_{1}, T_{5}\right)$, and several saturation limiters $\left(S_{1}, \ldots, S_{5}\right)$. Hence, the control structure differs from models commonly used in transient analyses such as the AVR 'DC1A' [6].

\subsection{Speed controller}

The common drives of CHPs are gas or diesel engines. Therefore, an engine needs to be emulated in order to mimic a realistic inertia of

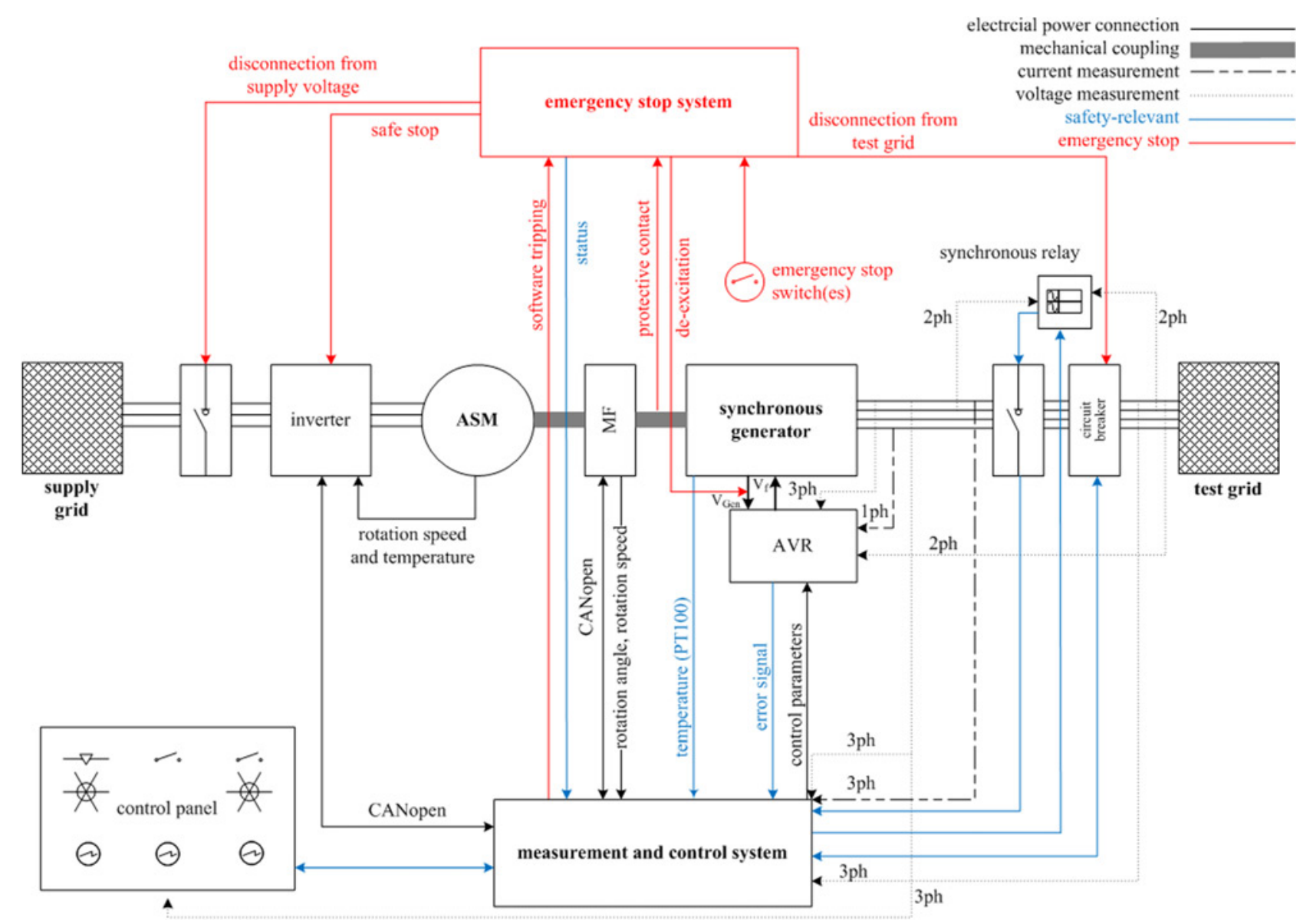

Fig. 3 Set-up of the component's signal exchanges 


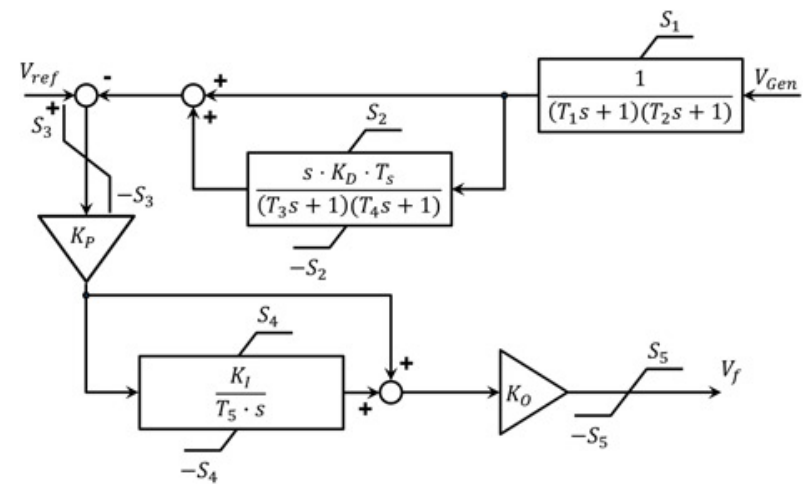

Fig. 4 Control scheme of the AVR 'MEC-100B' [5]

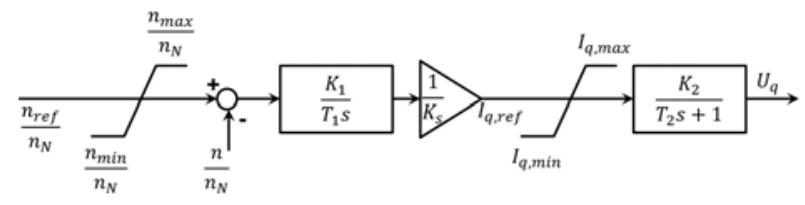

Fig. 5 Control scheme of the speed controller

the overall system. As a proof of concept and in order to demonstrate the potential of the highly dynamic drive, the inverter's standard speed controller is used (Fig. 5). The controller limits the relative set speed $n_{\text {ref }} / n_{N}$ with the preset limits $n_{\max }$ and $n_{\min }$ and then subtracts the current speed $n$. With the help of a proportionalintegral (PI) controller $\left(K_{1}, T_{1}\right)$ and a proportional amplifier $\left(1 / K_{\mathrm{S}}\right)$, a reference value for the quadrature current $I_{\mathrm{q}, \text { re }}$ is calculated and limited $\left(I_{\mathrm{q}, \max }, I_{\mathrm{q}, \min }\right)$. The second PI controller $\left(K_{2}, T_{2}\right)$ controls the current to set the quadrature voltage $U_{\mathrm{q}}$ of the ASM.

For the islanded operation, the speed controller is set to a nominal speed of $1500 \mathrm{rpm}$ in order to keep the nominal frequency of $50 \mathrm{~Hz}$. The authors emphasise that this controller does not reflect the transient behaviour (inertia) of a real gas engine and is used only for the demonstration of the dynamic capabilities of the drive.

\section{Test results}

\subsection{Laboratory set-up}

In order to demonstrate the operability of the test stand, a simple test set-up for an islanded operation has been designed as a proof of concept. As shown in Fig. 6, the SG is directly coupled to a three-phase resistive-inductive load bank using four single conductors $\left(35 \mathrm{~mm}^{2}\right)$ including the neutral conductor with $\left|\underline{Z}_{L}\right|$ $\simeq R_{L}=1.53 \mathrm{~m} \Omega$ each. The load bank is able to provide a maximum active load of $15 \mathrm{~kW}$ and inductive load of $5.7 \mathrm{kVAr}$ (single phase).

\subsection{Experimental design}

To demonstrate the dynamic performance of the test stand, the load variations shown in Fig. 7 are applied to the test stand using the resistive-inductive load bank. Until $t=90 \mathrm{~s}$, the active power is set either to 24 or $45 \mathrm{~kW}$ - the first being $\sim 50 \%$ of the nominal power and therefore representing the minimum value of a typical

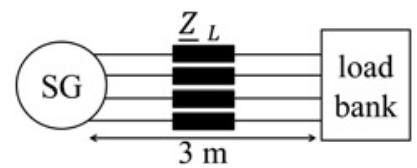

Fig. 6 Laboratory test set-up for an islanded operation

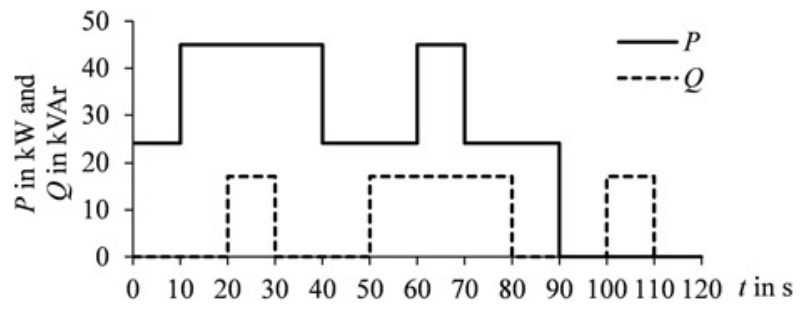

Fig. 7 Resistive-inductive load variations for dynamic test

gas engine and the latter being almost the maximum nominal power of the whole test stand. The reactive power is set either to 0 or $17.1 \mathrm{kVAr}$, which is the load bank's maximum. These values are chosen to realise the maximum load variations possible using this resistive-inductive load bank. At the same time, the power factor $\cos \varphi$ does not fall below 0.8, thus staying in the test stand's limits and still applying for a realistic maximum power factor in low voltage ( $\cos \varphi \geq 0.95$ [7]) and in medium-voltage grids $(\cos \varphi \geq 0.9$ [8]). For $t>90 \mathrm{~s}$, a rather academic phase shifting operation for future applications is applied.

\subsection{Results}

The measurements shown in Fig. 8 were recorded at the point of common coupling (PCC) of the SG. They demonstrate the highly dynamic performance of the test stand: the maximum overshoots recorded are $\widehat{P}_{\text {oversh. }} \simeq 3.3 \mathrm{~kW}$ and $\widehat{Q}_{\text {oversh. }} \simeq 11.1 \mathrm{kVAr}$, still being in the test stand's limits. Both $P(t)$ and $Q(t)$ (Fig. 7) are supplied with almost no delay (Fig. $8 a$ ). The maximum settling time of $P(t)$ is $t_{\text {settl. }, P} \simeq 1.7 \mathrm{~s}$ (Fig. $8 b$ ) and the maximum settling time of $Q(t)$ is $t_{\text {settl. }, O} \simeq 2.3 \mathrm{~s}$ (Fig. $8 c$ ).

As expected, the test stand does prove to be much 'faster' (low inertia) in its settling times than a common CHP with a gas or diesel engine [9]. Applying a higher inertia can easily be achieved by a software implementation in the measurement and control system using different speed or torque controls for the CHP emulation (e.g. [9]).
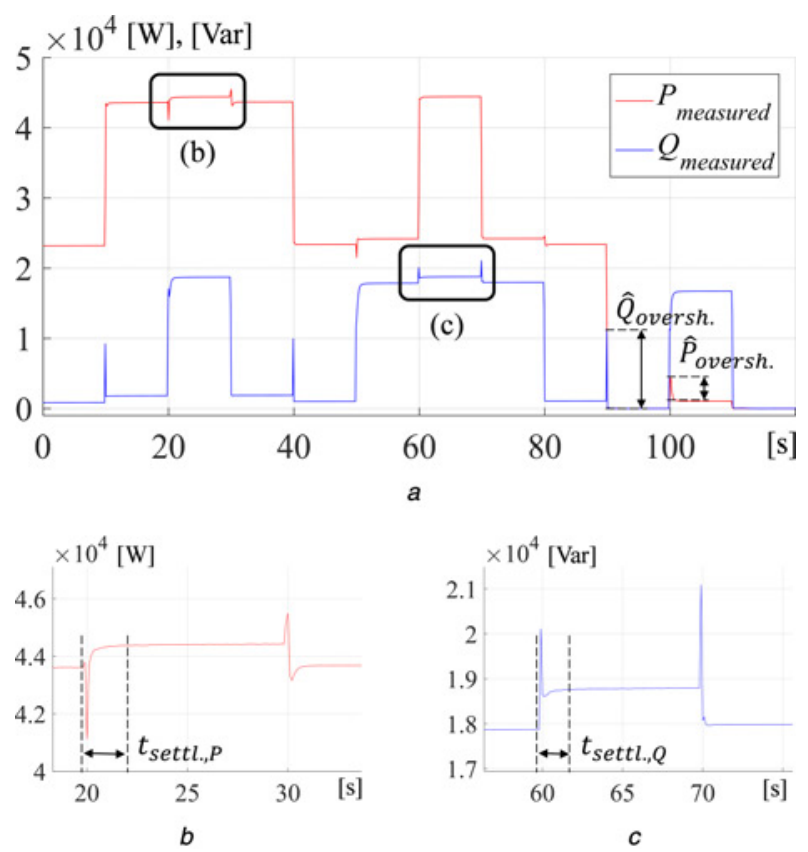

Fig. 8 Measurement results for the test experiment for (a) The whole experiment and for exemplary zoom into transients for, (b) Active power, (c) Reactive power 


\section{Conclusion and outlook}

\subsection{Conclusion}

In this paper, a CHP test stand design and implementation is shown. The modular design can be used to investigate a large variety of different drives and synchronous generators. An exemplary laboratory test is presented and the drive can prove its highly dynamic performance. The set-up can be used for the emulation of a large variety of engines and governors in future validation and stability studies. Overall, the layout can be used as a draft for similar research works in the field of laboratory CHP test stands of the same power range. For test stands with higher powers, the overall configuration (especially the set-up of the mechanical parts) should be reconsidered.

\subsection{Outlook}

With the help of this test stand design, manifold dynamic CHP models can be validated for transient stability studies taking into account ADGs with a high number of DERs. The authors will focus on the investigation of the dynamic behaviour of different SGs, on the combination of SGs with inverter interfaced DERs, as well as on the investigation of new control concepts for islanded grids.

\section{Acknowledgments}

This work was sponsored by the German Federal Ministry of Education and Research under grant number 03EK3568A (research project 'SwarmGrid'). The authors gratefully appreciate the help of Stefan Erkens in designing and implementing the test stand.

\section{References}

1 Altschäffl, S., Witzmann, R.: 'A modelling approach for dynamic short-circuit analysis of the German power system considering all voltage levels'. Int. ETG Congress 2015 Proc., 2015, pp. 129-136

2 Boemer, J.C.: 'On stability of sustainable power systems: network fault response of transmission systems with very high penetration of distributed generation'. Dissertation, Delft University of Technology, Delft, 2016

3 Salman, A., Dallmer-Zerbe, K., Singer, R., et al.: 'Large-disturbance voltage stability of SG applying FGW TR4-models in distribution grids'. 2016 IEEE Int. Energy Conf. (ENERGYCON), 2016

4 Boemer, J.C., Torres, J.L.R., van Ruitenbeek, E., et al.: 'Weiterentwicklung des Verhaltens von Erzeugungsanlagen am Niederspan-nungsnetz im Fehlerfall: Systemsicherheitsaspekte'. Forum Netztechnik/Netzbetrieb im VDE (FNN), Berlin, 2013

5 MarelliMotori: 'MEC-100 digital regulation system: mathematical model', 2009

6 IEEE recommended practice for excitation system models for power system stability studies, 1992

7 VDE Verband der Elektrotechnik Elektronik Informati-onstechnik e.V.: 'Erzeugungsanlagen am Niederspan-nungsnetz $\quad-$ Technische Mindestanforderungen für An-schluss und Parallelbetrieb von Erzeugungsanlagen am Niederspannungsgnetz'. VDE-AR-N 4105, 4105, 2011

8 BDEW Bundesverband der Energie- und Wasserwirt-schaft e.V.: 'Technische Richtlinie: Erzeugungsanlagen am Mittelspannungsnetz’. Richtlinie für Anschluss und Parallelbetrieb von Erzeugungsanlagen am Mittelspannungs-netz, 2008

9 Neely, J.C., Pekarek, S., Glover, S., et al.: 'An economical diesel engine emulator for micro-grid research'. 2012 Int. Symp. on Power Electronics, Electrical Drives, Automation and Motion (SPEEDAM 2012), 2012, pp. 175-179

\section{Appendix}

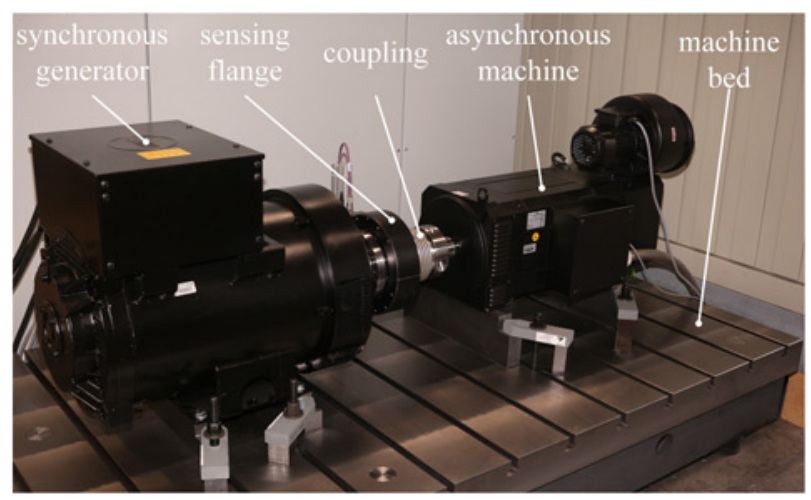

Fig. 9 Test stand set-up with an exemplary $84 \mathrm{~kW}$ synchronous generator according to Fig. 1

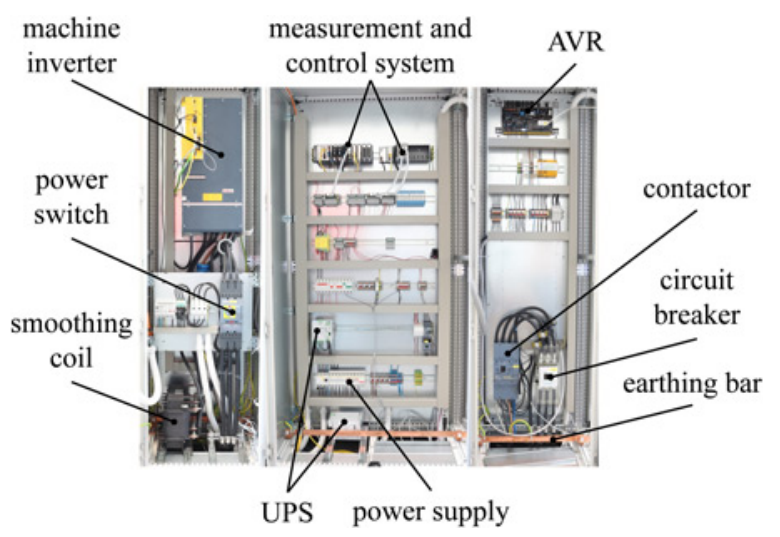

Fig. 10 Control cabinets with a machine part (left), a wiring and control part (middle), and a generator part (right)

Table 1 Main components used for specific test stand set-up

\begin{tabular}{lcc}
\hline Component & Product & Company \\
\hline synchronous generator & MJB 225 MA4 & Marelli Motori \\
AVR & MEC-100B & Marelli Motori \\
asynchronous machine & DA 160 M 23 R & Baumüller \\
machine inverter & b maXX BM5554 & Baumüller \\
sensing flange & T12 & HBM \\
coupling & BK8-1500 & R +W \\
measurement and control system & cRIO-9039 & National Instruments
\end{tabular}

